\title{
Article
}

\section{Comment on: "The Use of Microtechnology to Quantify the Peak Match Demands of the Football Codes: A Systematic Review"}

Carling, C., McCall, A., Harper, D., and Bradley, P.S.

Available at http://clok.uclan.ac.uk/24873/

Carling, C. ORCID: 0000-0002-7456-3493, McCall, A., Harper, D., and Bradley, P.S. (2018) Comment on: "The Use of Microtechnology to Quantify the Peak Match Demands of the Football Codes: A Systematic Review". Sports Medicine . ISSN 0112-1642

It is advisable to refer to the publisher's version if you intend to cite from the work. http://dx.doi.org/10.1007/s40279-018-1032-z

For more information about UCLan's research in this area go to http://www.uclan.ac.uk/researchgroups/ and search for <name of research Group>.

For information about Research generally at UCLan please go to http://www.uclan.ac.uk/research/

All outputs in CLoK are protected by Intellectual Property Rights law, including Copyright law. Copyright, IPR and Moral Rights for the works on this site are retained by the individual authors and/or other copyright owners. Terms and conditions for use of this material are defined in the policies page. 
Title: Comment on: "The Use of Microtechnology to Quantify the Peak Match Demands of the Football Codes: A Systematic Review."

Running head: Physical performance in the football codes

Authors: ${ }^{1}$ Christopher Carling, ${ }^{2,3}$ Alan McCall, ${ }^{4}$ Damian Harper, ${ }^{5}$ Paul S. Bradley

Institutions:

${ }^{1}$ Institute of Coaching and Performance, University of Central Lancashire, Preston, UK.

${ }^{2}$ Faculty of Health, Life \& Social Sciences, Research Department for Sports and Exercise Science, Edinburgh Napier University, UK;

${ }^{3}$ Arsenal Football Club, Performance and Research Department, London, UK.

${ }^{4}$ School of Sport, York St John University, York, UK.

${ }^{5}$ Research Institute for Sport and Exercise Sciences, Liverpool John Moores University, Liverpool, UK.

Correspondence:

Christopher Carling, Institute of Coaching and Performance, University of Central Lancashire, Preston, UK.

Phone: +44 (0)1772 891998

Email: ccarling@uclan.ac.uk

ORCID iD: 0000-0002-7456-3493 
Title: Comment on: "The Use of Microtechnology to Quantify the Peak Match Demands of the Football Codes: A Systematic Review."

\section{Dear Editor,}

We read with interest a recent review ${ }^{[1]}$ on the use of microtechnology to quantify peak physical match demands in the football codes. This paper provides information across playing standards and positions, and identifies the variables and study designs employed to achieve this. The authors notably conclude that quantification of the peak match demands across the football codes is useful for the prescription of physical conditioning drills to prepare players for the most intense periods of match-play. They also recommend that prescription is specific to code and playing position. In light of their findings and conclusions, it is our view that further debate and additional research are necessary in relation to player monitoring and conditioning.

First, the authors restricted their analysis to studies using 'wearable' microtechnologies to analyse peak demands. We are unclear as to the rationale for the omission of several key studies ${ }^{[2-9]}$ using valid and reliable passive manual and optical tracking techniques to quantify peak locomotor demands in elite male and female soccer players. Indeed, the use of commercial optical tracking systems (e.g., STATS, TRACAB) for monitoring contemporary competitive performance is ubiquitous, especially in European professional soccer leagues. It is also noteworthy that these investigations mainly included first-team player cohorts from the highest standard of European soccer leagues, which frequently was not the case in the aforementioned review. Although these studies mostly employed segmental analysis of match time-periods which the authors highlight underestimate peak running activity, in our opinion, their inclusion would have provided additional information for soccer and position-specific profiling. This includes for example, variations in peak activity demands across playing standards, their temporal occurrence, effects of substitutions, and transient reductions in running output within and immediately following peak periods.

In their review, the authors suggest that determining peak match activity demands can establish the 'worst-case scenario' for individual variables thereby aiding training prescription. While such information might have implications for designing isolated high-intensity training and return to play drills and fitness tests, in our experience it is still unclear if and how practitioners in the football codes integrate such information into their physical conditioning regimens. Are "one-off" or multiple repetitions of isolated high-intensity drills utilised in an attempt to replicate the peak demands of their code over the course of sessions? Alternatively, do practitioners aim to ensure via monitoring of matchrelated drills such as small-sided games that players regularly replicate or even overload the peak demands identified in match-play? Research comparing peak competition demands compared to those actually generated in conditioning practice is lacking. ${ }^{[10]}$ Future research should report on how many occasions within and between matches players perform a volume of activity that is not too dissimilar to the identified peak period of activity. Arguably this information would be useful to elucidate whether these peak demands are 'one-off', especially as match-to-match variability in this metric is substantial $(\mathrm{CV}=\sim 24 \%)^{[11]}$, thereby aiding decision-making on the real-world need (and if so, informing content) for specific conditioning sessions.

The authors identified multiple variables used to assess peak-match demands - mainly duration- and velocity-specific movements - while suggesting there is need for alternative information (e.g. collisions and accelerations) in addition to the locomotive variables. Research not cited by the authors and we feel merited discussion includes the duration (e.g., <30s, 31-60s, and >61s intervals) and type (passive versus active) of recovery between consecutive high-intensity actions within peak periods. ${ }^{[5]}$ Another omitted investigation $^{[12]}$ examined decrements in maximal sprinting velocity (using individualised sprinting thresholds tailored to each player's peak velocity) across consecutive sprints in the most intense bouts of activity. 
The authors rightly point out the need for concomitant analyses of technical-tactical demands alongside physical demands during peak activity periods, yet in our opinion missed an opportunity to discuss recent papers on the integration of physical-tactical-technical metrics. ${ }^{[13-16]}$ The reductionist approach to focussing upon 'blind' distances during intensified periods for example has been used for several decades (mea culpa also for some of the authors of this letter!). Although we recognise that the authors have acknowledged some shortcomings in their review, we are still no nearer to understanding how peak data can be translated into training without specific context added to drills based on the football code, playing position and individual. Prescription metrics for relatively closed drills cannot be based on simple frequencies and blind robotic distances but are dependent upon tactical stimulus and subsequently angles of turns, associated technical skills, typical action location, and interactions with opposition and teammates. A recent paper provided inclusion criteria for contextualised activities: context occurred in $>33 \%$ of intense efforts during periods and the contextual factors for a selected position were at least a moderate effect size difference compared to a minimum of two other positions. ${ }^{[16]}$

The authors reported differences in peak demands across playing positions in all the football codes. These differences were dependent upon the variables analysed, suggesting prescription of fitness training should be position-specific. Unfortunately these points were not developed in their discussion. Should practitioners analyse selected variables for peak periods specifically in relation to the demands of playing positions, for example hard accelerations and distance covered at high-speeds for fullbacks versus 'player load' for central defenders ? $^{[17]}$ Doubts have been expressed regarding the sensitivity of data-driven approaches to determining positional demands and their eventual application in fitness training interventions particularly in soccer. ${ }^{[18]}$ The magnitude in real-world terms of the differences in peak activity demands across positions in the various football codes reported by the authors might be questionable as regards the necessity for systematic training prescriptions especially for every individual position. Another key question is whether practitioners should use the highest identified peak activity period observed across all players, irrespective of positional role, to tailor conditioning sessions? Alternatively, should conditioning for peak demands be based on individual rather than positional data?

Finally, the authors state that studies with multiple clubs are required to provide generalisable information on peak match demands. In our experience, results obtained from large samples cannot be easily generalised to individual contexts. Large inter-club disparities exist in the physical, tactical and technical abilities of players making up squads, and cultural and philosophical differences in practitioners' approach to training and competition arguably leading to doubts about the pertinence and practical applicability of any large-scale dataset for a single club setting.

Compliance with Ethical Standards

Funding

No sources of funding were used to assist in the preparation of this letter.

Conflicts of Interest

Christopher Carling, Alan McCall, Damian Harper and Paul Bradley declare that they have no conflicts of interest relevant to the content of this letter.

References:

1. Whitehead S, Till K, Weaving D, Jones B. The use of microtechnology to quantify the peak match demands of the football codes: a systematic review. Sports Med. First online 7 August 2018. https://doi.org/10.1007/s40279-018-0965-6.

2. Bradley PS, Dellal A, Mohr M, Castellano J, Wilkie A. Gender differences in match performance characteristics of soccer players competing in the UEFA Champions League. Hum Mov Sci. 2014;33:159-71.

3. Bradley PS, Di Mascio M, Peart D, Olsen P, Sheldon B. High-Intensity activity profiles of elite soccer players at different performance levels. J Strength Cond Res. 2010;24:2343-51.

4. Bradley PS, Sheldon W, Wooster B, et al. High-intensity running in English FA Premier League soccer matches. J Sports Sci. 2009;27:159-68. 
5. Carling C, Le Gall, F, Dupont G. Analysis of repeated high-intensity running performance in professional soccer, J Sports Sci. 2012;30:325-36.

6. Di Mascio M, Bradley PS. Evaluation of the most intense high-intensity running period in English FA premier league soccer matches. J Strength Cond Res. 2013;27:909-15.

7. Fransson D, Krustrup P, Mohr M. Running intensity fluctuations indicate temporary performance decrement in top-class football. Sci Med Football. 2017;1:10-17.

8. Mohr M, Krustrup P, Andersson H, Kirkendal D, Bangsbo J. Match activities of elite women soccer players at different performance levels. J Strength Cond Res. 2008;22:341-9.

9. Mohr M, Krustrup P, Bangsbo J. Match performance of high standard soccer players with special reference to development of fatigue. J Sports Sci. 2003;21:519-28.

10. Stevens TGA, de Ruiter CJ, Twisk JWR, Savelsbergh GJP, Beek PJ. Quantification of in-season training load relative to match load in professional Dutch Eredivisie football players. Sci Med Football. 2017;1:117-25.

11. Carling C, Bradley P, McCall A, Dupont G. Match-to-match variability in high-speed running activity in a professional soccer team. J Sports Sci. 2016;34:2215-23.

12. Schimpchen J, Skorski S, Nopp S, Meyer T. Are "classical" tests of repeated-sprint ability in football externally valid? A new approach to determine in-game sprinting behaviour in elite football players. J Sports Sci. 2015;34:519-26.

13. Ade J, Fitzpatrick J, Bradley PS. High-intensity efforts in elite soccer matches and associated movement patterns, technical skills and tactical actions. Information for position-specific training drills. J Sports Sci. 2016;34:2205-14.

14. Bradley PS, Ade JD. Are current physical match performance metrics in elite soccer fit for purpose or is the adoption of an integrated approach needed? Int J Sports Physiol Perform. 2018;13:656-64.

15. Bradley PS, Di Mascio, M, Mohr, M, Fransson, D, Wells, C, Moreira, A, et al. Can modern trends in elite football match demands be translated into novel training and testing modes? Aspetar Sports Med J. 2018;7;46-52.

16. Bradley PS, Evans M, Laws A, Ade JD. 'Context is King' when interpreting match physical performances. Football Medic \& Scientist. 2018;24:42-45.

17. Dalen T, Ingebrigtsen J, Ettema G, Hjelde GH, Wisløff U. Player load, acceleration, and deceleration during forty-five competitive matches of elite soccer. J Strength Cond Res. 2016;30:351-9.

18. Carling C. Interpreting physical performance in professional soccer match-play: should we be more pragmatic in our approach? Sports Med. 2013;43:655-63. 